\title{
Os sentidos caligráficos em Hilal Sami Hilal. Por uma proposta de pintescritura
}

Marco Antônio Vieira

Universidade de Brasília

\section{Resumo}

É em torno do costeiro, do litorâneo, zona de contaminação a ecoar a lição lacaniana, que se enredam as tramas de um texto em que o poético oscila entre a língua e a imagem. $\mathrm{O}$ (des)fiar narrativo, circular e plurivocal das obras do artista visual Hilal Sami Hilal em que o verbal assume, por meio de inscrições alfabéticas oxidadas, a aparência de notações a beirar o hieroglífico torna-se alegoria, uma vez que encerra a questão, insistente e fantasmal, da leitura de obras de arte a partir de uma análise comparativa e contrastiva de diferentes sistemas semióticos. Ocupam-nos aqui alguns modos pelos quais literatura e visualidade copulam caligráficos a produzir sentidos na materialidade do que batizamos pintescritura.

\section{Palavras-chave}

Hilal Sami Hilal. Intersemiose. Teoria e História da Arte. Literatura. Giro Pictórico.

\begin{abstract}
Circling the coastal boundaries, a zone of contamination echoing the Lacanian lesson, are the textual webs to be found in which the poetical oscillates between language and the image. The narrative, circular and plurivocal (un)veiling of the works coined by Hilal Sami Hilal, a Brazilian visual artist, in which the verbal takes on, by means of oxidized alphabetic inscriptions, an appearance which verges on the hieroglyphic, becomes allegory, once it embeds the insistent and phantasmal question of the rendition of works of art centred around a comparative and contrastive analysis of different semiotic systems. This text occupies itself with a few of the manners in which literature and visuality copulate calligraphic breeding meaning in the materiality of what is herein baptized paintscripture.
\end{abstract}

\section{Keywords}

Hilal Sami Hilal. Intersemiosis. History and Theory of Art. Literature. Pictorial Turn. 


\section{Pintescritura: arremedo de um prelúdio ou o que se faz necessário}

Este texto extrai o seu título de uma investigação em nível de Mestrado (VIEIRA, 2004), em que, sobre um pano de fundo teórico de inspiração lacaniana, inquire-se da picturalidade na literatura de Virginia Woolf e no cinema de Peter Greenaway. "Lituraterra" (LACAN, 2001, p.15-29), o texto que Lacan escreve após seu retorno de uma viagem ao Japão cuja vista aérea o leva a refletir em torno das noções dos limites e fronteiras entre água e terra atrelados à insularidade topológica nipônica e promove um paralelismo entre o ideograma - sua iconicidade inacessível a um ocidental - e seu conceito de letra, ao qual Lacan opõe aquele de significante. Se o significante lacaniano "representa o sujeito para outro significante", enfatizando-se assim o enredamento nas malhas da linguagem a que nos assujeitamos, a letra revela algo dos restos do Real, flerta com o gozo e objeto a, convocando à cena teórica lacaniana o inominável, o irrepresentável, o que estaria além de qualquer possibilidade de simbolização.

Etimológica e filologicamente, Lacan explora a ambiguidade semântica do vocábulo lettre, que, em francês, significa a um só tempo carta e letra, uma ambivalência já investigada pelo psicanalista francês em O "Seminário sobre a Carta Roubada" (LACAN, 1998). No texto mais antigo, expõe-se a complexidade significante de um conto de Edgard Alan Poe em que a personagem principal da narrativa, para Lacan, é a carta/letra cujo conteúdo é desconhecido mas que mobiliza toda a ação das personagens da trama, impulsionadas e impelidas pelo desejo de aceder à carta para ocupar um lugar que, a rigor, é inacessível pois que sua obtenção representaria a quebra da cadeia significante. 
Dito de outro modo, aquilo que a carta enseja é nada senão uma função que permite e autoriza que o jogo significante possa manter-se em nome de uma significação que, de resto, encontra-se fada à incompletude mas que precisa insistir. $O$ enredo é aqui enredamento e não há metalinguagem possível para o sujeito que não é transparente para si mesmo em sua posição significante. A carta é então letra, um quase utensílio, quase hieróglifo. Sua tradução enreda-se, labiríntica, à maneira de ecos e reenvios à própria estrutura que autoriza a significação.

Em "Lituraterra", Lacan parte da noção da literature de James Joyce, a qual, em sua concepção, é uma literatura de restos, apanhados nas redes da linguagem. O título do texto advém das palavras latinas litura: parte de um escrito que se torna ilegível por se haver apagado ou riscado e de liturarius, o que traz rasuras, o rascunho, estado primeiro de um escrito. É, pois, sobre esse mito de uma origem que se traveste palimpsesta que escorrem os fios da trama de nosso assujeitamento à linguagem de onde este texto busca ancoragem e sustentação.

Interessa-nos, igualmente, para a composição da tessitura do pano de fundo teórico, contra o qual se desenrola a cena de nossa argumentação as elaborações de W. J. T. Mitchell em seus Iconology, Picture Theory, What do Pictures Want e Image Science - Iconology, Visual Culture and Media Aesthetics, em que o autor estabelece o marco do giro ou virada pictórico, o qual se contraporia ao giro ou virada linguístico que marcara as decadas de 60 e sobretudo 70 do século XX nas ciências humanas, em particular, na História e na Literatura. Mitchell reflete ainda em torno da distinção imagem (phantasia) e quadro/pintura/artefato (eikon) e procura estabelecer os fundamentos de uma "ciência das imagens" (MITCHELL, 2015): 
I will employ the typographic convention of the slash to designate the "image/text" as a problematic gap, cleavage, or rupture in representation. The term "imagetext" designates composite, synthetic works (or concepts) that combine image and text. "Image-Text", with a hyphen, designates relations the visual and verbal. (MITCHELL, 1994, 89).

Muito do que aqui se deslinda advém de Lacan, de Mitchell e do conceito de verbivocovisualidade presente na Poesia Concreta brasileira (ARAÚJO, 1999), assim como no Concretismo e Neo-Concretismo nacionais. Interessa ainda a vanguarda poético-visual que marca a fronteira entre os anos 60 e 70 no Brasil do Poema/Processo em Waldemir Dias-Pino e Neide de Sá, por exemplo: ... "designação em sintonia préclara com a arte transformadora da época em que o privilégio das formas em trânsito, marcavam a mais instigante produção imagetica ..." ( NAVAS In: MARGUTTI, 2014, p.10, grifo nosso). Ainda, segundo Navas:

Neste novo poema ampliado de forma inaugural, com o desafio de uma nova pré-linguagem, o movimento abriuse para uma correlação de signos, imagens e textualidades, através de uma rigorosa e também libertária codificação de sinais, que fazia da comunhão de iconografia, texto e imagens seu verdadeiro corpus propulsor...(NAVAS, op.cit. p.10).

Ampara-se este texto em uma apreensão da caligrafia como repositório e síntese a um só tempo materiais e alegóricos do desenho argumentative que se propõe para este texto. Seu lugar fundante nas culturas letradas chinesa e árabe, por exemplo e a importância da noção de "texto-imagem" em Mitchell nos manuscritos e iluminuras do Medievo no Ocidente. A mitificação hierática do caligráfico, pois que ancorada nas escrituras que inscrevem o sagrado nas civilizações pretéritas. Sua inserção inegavelmente ideológica, uma vez que responsável pelo registro, 
pela preservação, a manutençao mesma da lei em sua multifacetada significação: religiosa, jurídica, societal. Sobretudo, a caligrafia fornece-nos a fronteira exata e portanto tão mais inacessível do impensado de uma invenção de um sistema que põe em circulação sinais, signos, inscrições que, esquece-se com espantosa facilidade, dependem de uma materialidade, de uma materialidade plástica mesmo para que existam.

Os ideogramas primeiros da cultura chinesa, aqueles que o Imperador $\mathrm{Fu}$ Xi tenta fixar como um sistema de notação de tudo que havia entre o céu e a terra, tudo o que, em tese, corresponderia analogicamente é bem lembrar- aos princípios negativos e negativos no universe, o yang e o yin, constroem-se em torno de oito combinações a representar o céu, a terra, o trovão, o vento, a água, o fogo, as montanhas e os rios. Fu Xi complete seu sistema regrupando numerosos objetos sob um mesmo símbolo, assim o signo (-) representa o céu, o imperador, o pai, o ouro, a cabeça e o cavalo. O signo (--) equivale à terra, à mãe, à vestimenta, à vaca, etc. Tal descrição deveria bastar como constatação das relações plurais e complexas que se infiltram na escrita: letras do alfabeto, ou a iconicidade em notação de ideogramas. 


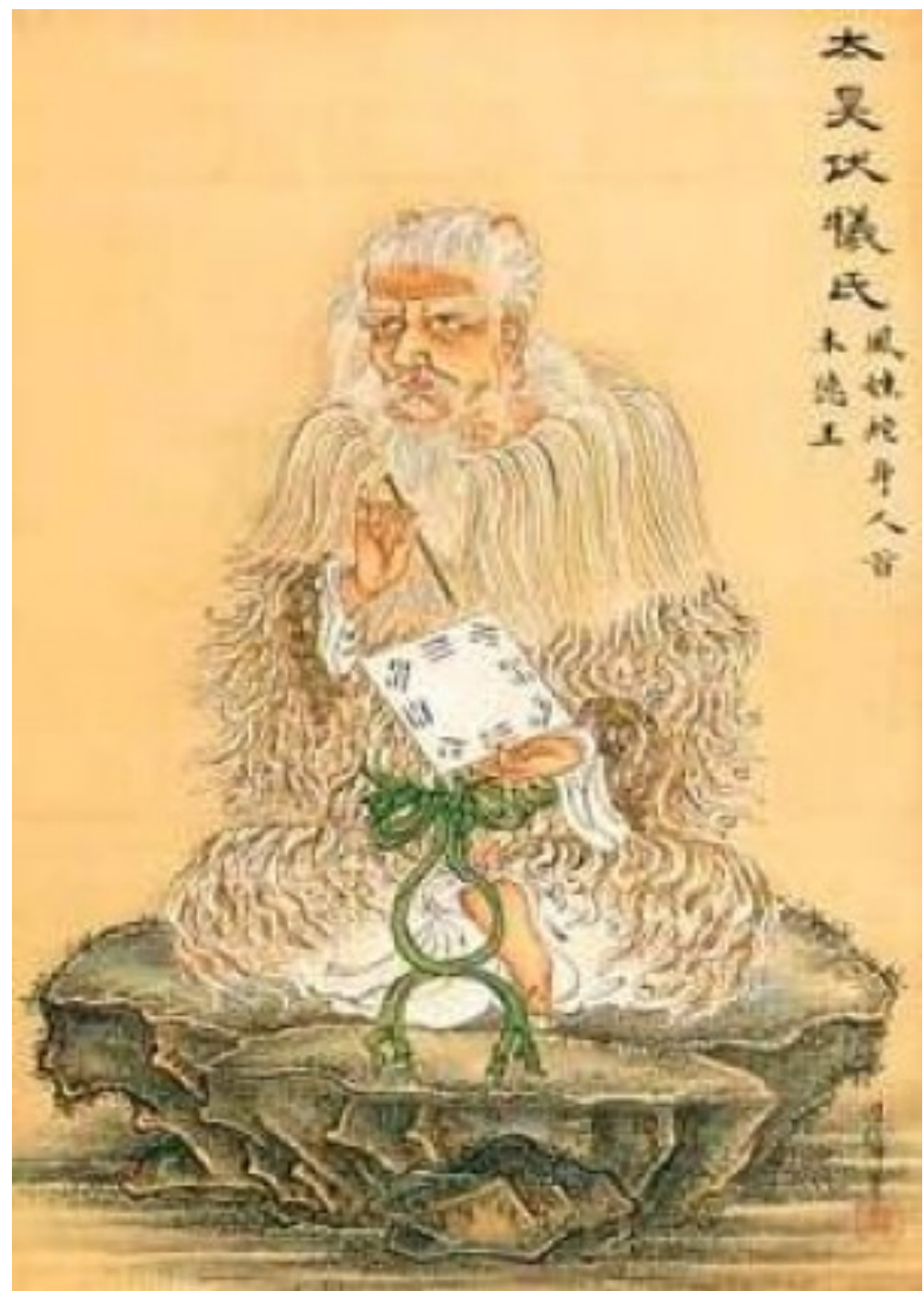

O imperador Fu Xi, Paris. Biblioteca Nacional da França

Não bastassem estas constatações de fundo filosófico e linguístico, aqui inseparáveis a bem dizer, a escrita - um quase-sinônimo do caligráfico como se o vê em nossa visada - depende de uma materialidade plástica quem em tudo a aproxima em sua origem do pictórico. A escrita caligráfica, a arte da caligrafia encontrava-se no ápice do edfício civilizatório para os chineses - os inventores dos ideogramas adotados no Japão e na Coréia - assim como no mundo árabe a partir da instauração do Islão, em que o religioso e o estético irmanam-se para o estabelecimento da escrita como um elemento iconográfico essencial para 
uma cultura que banira da cena representacional o figurativismo, de vez que o Corão proscreve o imitativo cujo referente mantenha vínculos com a figura.

Na China, imagem (eikon) e caligrafia, assim como no Japão, constituem níveis indissociáveis da composição imagética/icônica. $\mathrm{Na}$ China, a caligrafia presidia às demais expressões artísticas. Para os chineses, os caracteres escriturais não se consituiam como entidades arbitrárias, mas sim representações de fenômenos naturais e a expressão de uma verdade essencial (MEDIAVILLA, 2004. p.20).

Complexos rituais de leitura divinatória tinham lugar na China Antiga. A descoberta e decifração de numerosas inscrições sobre ossos e carapaças e cascas de tartaruga permitiram situar a origem real da escrita chinesa. Os ossos e fragmentos que nos chegaram trazem em um dos lados signos incisos com o auxílio de um objeto pontiagudo, o outro lado apresentando craquelados certamente devidos ao fogo, sob cuja chama se liam estes sinais do vaticínio. O sacerdote aproximava cautelosamente as inscriçoes da chama. A resposta à questão devia deduzir-se da forma dos craquelados produzidas no verso do suporte. 
VIS

Revista do Programa de Pós-graduação em Arte da UnB

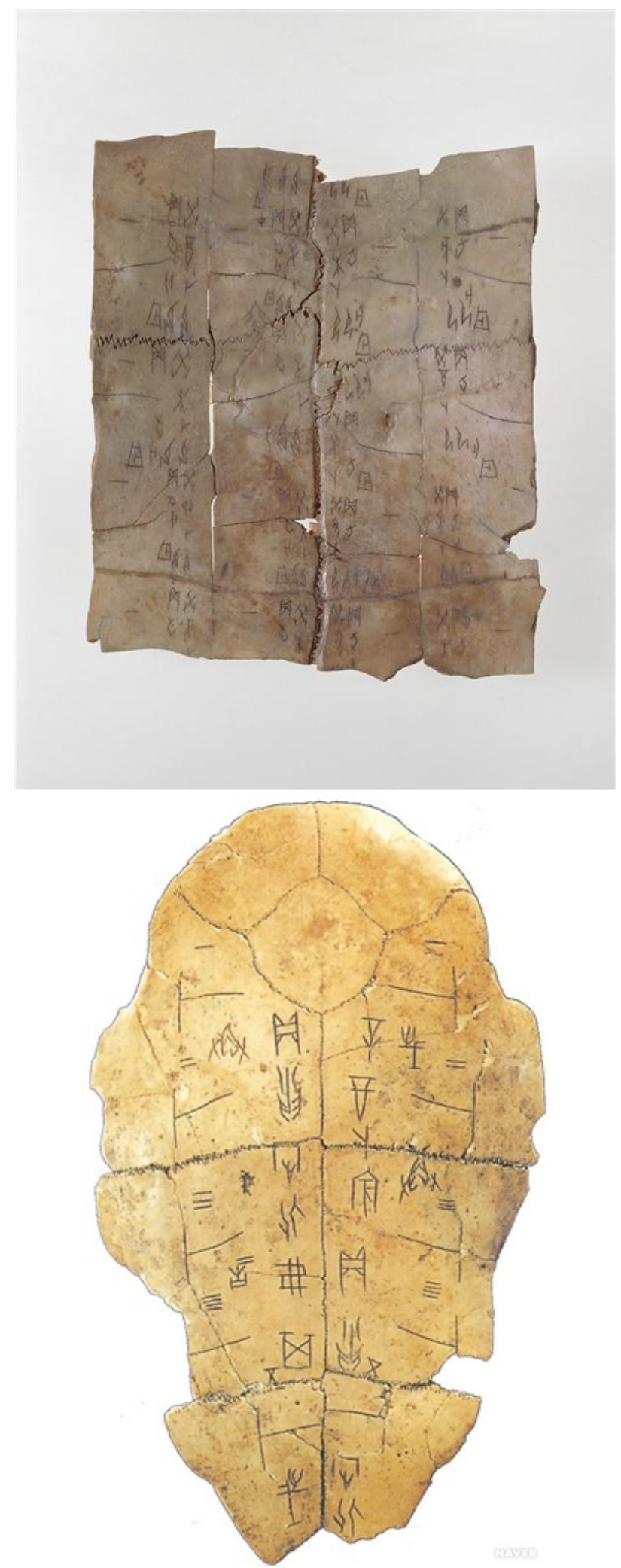

Ossos divinatórios chineses 


\section{Pintescritura: a caligrafia, o entre-histórias, a literatura e a imagem em} Hilal Sami Hilal

A um só tempo phantasia, em outras palavras, projeções que se desprendem dos efeitos do significante, uma imagem mental, por assim dizer, e eikon - a imagem física, encarnada, enquadrada, a pintura, talvez ou artefato imagético. Que se pense então, é o que se propõe aqui, nestas duas configuraçoes do vocábulo imagem como um fóssil vivo, marcado por tramas e veios e fios, novelos, rendilhados até de tempos que se cruzam sincrônicos, uma desterritorialização , uma intemporalidade das imagens, um curto-circuito sígnico, a seguirmos a lição que o filósofo e historiador da arte Georges Didi-Huberman (2015) retira do legado de Aby Warburg, o anacronismo que permite o trânsito spectral de fantasmas que atravessam paredes e redesenham o que de um terreno ou de um cômodo - a dit-mansion lacaniana (2003) - do histórico se faz aqui fronteira ou litoral.

Aquilo que borra e escorre como os céus ou massas atmosféricopictóricas marcados de laranja e chumbo em Turner, como no quadro "A manhã depois do dilúvio", em que um Moisés eclipsado pelas névoas de luz escreve o livro do Gênesis, a origem mítica do mundo, o que instaura uma escrita, escritura sagrada dos tempos, aquilo que, para nós, fulgura na oxidação metálica das letras - matéria em mais de um sentido - das obras de Hilal Sami Hilal Seu Sami (2007), em que se faz remissão à linhagem paterna e síria do artista. 


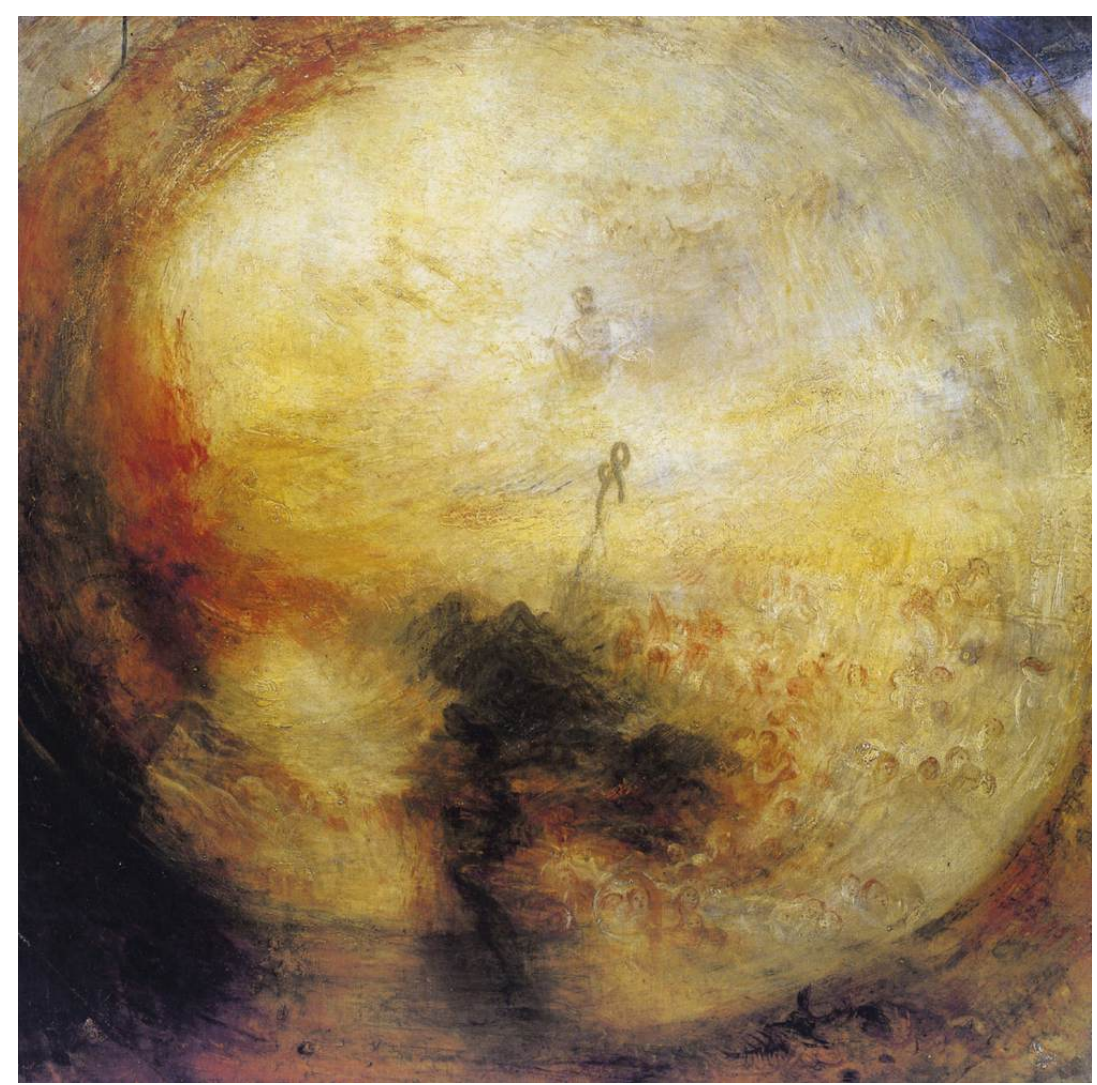

The morning after the deluge, Joseph Mallord William Turner, 1843.

Óleo sobre tela , 78,5 X 78,5 cm . Tate Gallery, Londres.

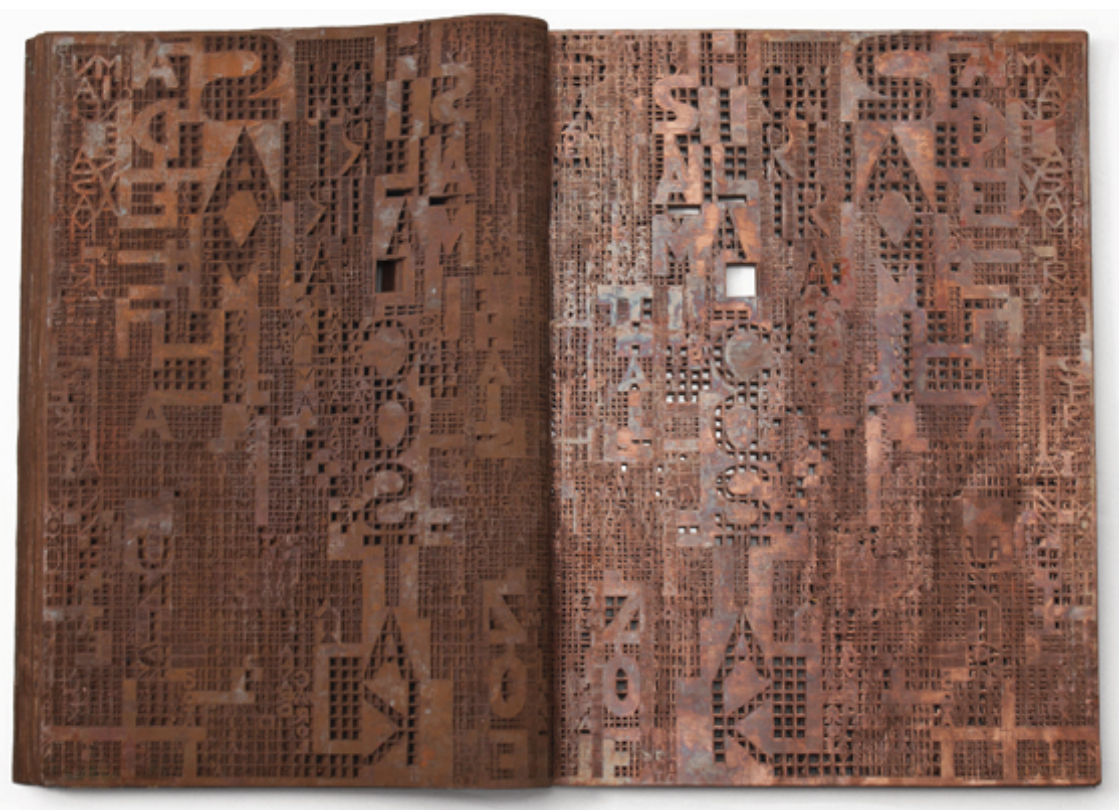

Seu Sami , Hilal Sami Hilal, 2007. Cobre , 63,5 x 48,5 x 3,5 cm . Coleção do Artista 
E aqui já se insinua o que nos interessa: a possibilidade de pensar a intersemiose como um campo de tensões e (in) determinações que se (re)configuram incessantemente moventes, fluídas, mutantes, metamorfoseadas. Pensar em que medida o poético para um além de sua inscrição filosófica ocidental primeira no literário (ARISTÓTELES, 2010) se estende, se expande, se alastra e contamina para insatalar-se naquilo que a tradição dos textos em culturas como a chinesa e árabe - sobretudo considera poético, o literário como indissociável de sua materialidade pictórica a constituir superficies e objetos híbridos, para que se retome Mitchell (1994, op.cit.) para um abraço, um encontro, um entrecruzar de olhares, uma cópula na materialidade e na visualidade caligráfica da escrita.

Uma textualidade híbrida - cuja leitura em nosso texto em tudo depende da alegoria em sua potência analógica- à maneira de iluminuras medievais em que, na página papírea, entrelaçam-se, qual arabescos que se enroscam como serpentes ou ramagens no corpo da letra e dela fazem testemunho visual que em tudo se aproxima da lógica do enxerto sígnico, o híbrido metastaseado como se o vislumbra em Arcimboldo ou na materialidade plástica do rébus do sonho em Sigmund Freud (2001). 


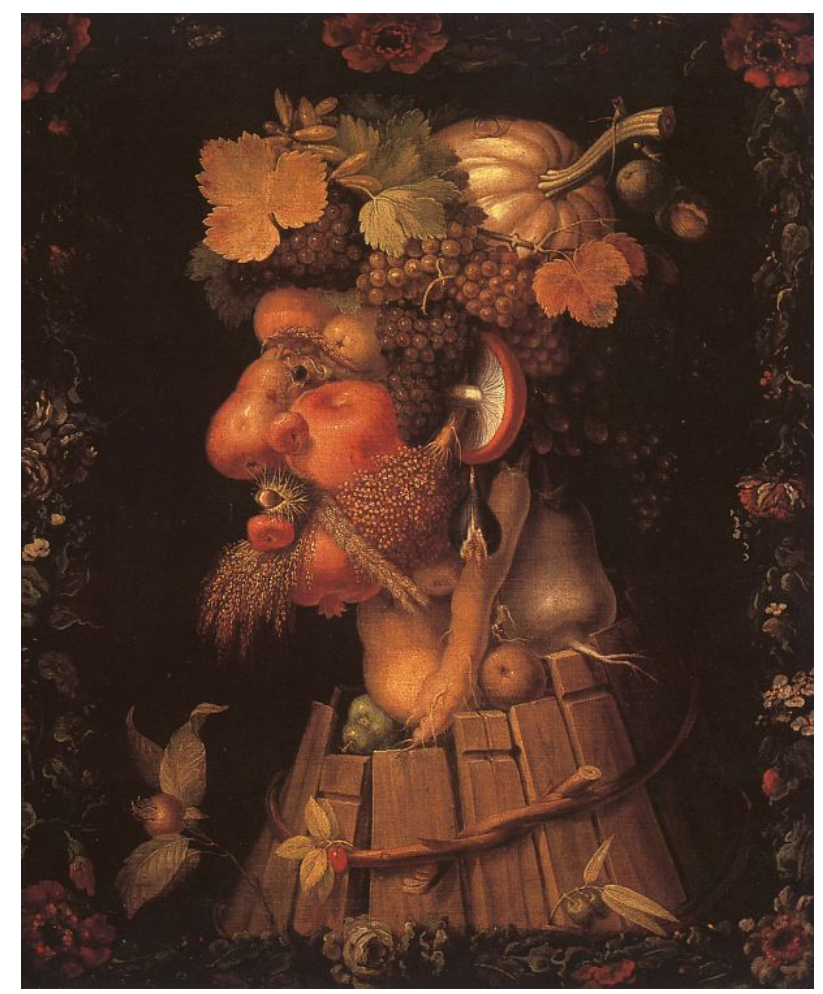

Outono, Giuseppe Arcimboldo, 1573

Óleo sobre tela , 76 × $64 \mathrm{~cm}$, Museu do Louvre, Paris.

Um turbilhão, um redemoinho de massas pictóricas que se inscrevem em uma escrita em torno do que me afeta na língua: estas reverberações aqui batizadas de poéticas - poiesis - aquilo que se escreve sob e sobre o sopro, sob e sobre a inspiração daquilo que nos atinge aistesis. Pintescrever, eis do que aqui se trata. Uma escrita em que copulem o icônico da letra e a fantasia de contornos ideogramáticos.

Ut pictura poesis, na pintura como na poesia ou ainda um poema é como um quadro, guardadas as devidas cautelas reservadas à toda a tradução, esta querela que se estendeu por séculos a fio em torno da supremacia da literatura em detrimento da pintura ou da pintura em detrimento da literatura:

A doutrina do ut pictura poesi, tal como se constituiu no Renascimento e se desenvolveu ao longo da época clássica, baseia-se num contra-senso, num erro de 
interpretação da frase da Epístola aos Pisãos: “ Ut picture poesis erit". Em Horácio, essa frase compara a poesia à pintura, fazendo desta última o termo referencial da comparação: um poema existe tal como um quadro. (LICHTENSTEIN, op. cit.).

É a Renascença que os teóricos invertem o sentido da comparação e estabelecem uma servidão da imagem em relação ao literário. No intuito de desvencilhar a pintura da mera mecanicidade irreflexiva a que o Medievo condenara a imagem, os renascentistas procuram investi-la dos artifícios da retórica e da poética e da dignidade intelectual associada ao logos. A pintura precisava confirmar-se como originada na Ideia, no intelecto, na teoria e não na matéria vulgar com que se via o ofício de pintar.

A pintura e a poesia agora irmanavam-se especularmente, a saber, a pintura seria uma "poesia muda" e a poesia uma "pintura falante", aqui portanto a poesia é apresentada com uma dupla determinação positiva ela é uma pintura a qual é concedida a palavra, a pintura é definida em negatividade, ou seja, falta-lhe a palavra. Submissão pictórica ao ordenamento logofonocêntrico. Leonardo da Vinci em o Trattato della Pittura, questionaria com veemência esta servidão da pintura.

Era preciso que se levassem em consideração as especificidades e as limitações de ambas a pintura e a poesia. A narrativa literária desdobra-se no tempo, ao passo que a questão determinante para a pintura é de ordem espacial. Todavia, parece-nos reducionista que nos atenhamosa um tal enclausuramento, de vez que uma cena, em particular a partir do que nos propõe Giotto adquire uma dimensão narrativa que igualmente aponta para uma espécie de congelamento temporal em que se advinha tanto o antes quanto o depois da encenação, à maneira da intensidade dramática 
da escultura grega no auge dos períodos clássico e helênico.

Em Laocoonte (LESSING, 2011), o filósofo romântico alemão contrapõe-se fervorosamente à possibilidade de pensar-se em paralelismos entre diferentes manifestações artísticas e advoga a preservação da especificidade de cada arte em sua singularidade expressiva. Clement Greenberg atualiza a discussão de Lessing ao defender, uma reiterada vez, em um artigo intitulado "Rumo a um mais novo Laocoonte", publicado em 1940 na Partisan Review, o quão o abstracionismo pictórico modernista reacendia a questão da especificidade de cada meio expressivo.

\section{Pintescritura: a intersemiose e a contemporaneidade}

Diante do que se acaba de expor, pareceria talvez incauto sustentar qualquer defesa em prol de um paralelo entre as artes. De fato, perseguir um fio argumentativo que se permitisse tramar com base em qualquer noção autoritária de hierarquização semiótica e de uma sua consequente subserviência de qualquer textualidade em favor de uma sua superior expressão invalidaria o argumento de antemão.

O que aqui se aventa aqui como exercício interpretativo parte a um só tempo do conceito de écfrase - a descrição de um quadro (eikon), por em movimento linguístico-verbal a cadeia significante encarregada de emprestar uma espécie de visualidade na língua (phantasia) - por meio de um exercício de tradução intersemiótica - ao visual, ao retiniano, ao ótico ; como também daquilo que nos propõem obras produzidas na contemporaneidade, suas configurações explicitamente híbridas e fronteiriças em que se borram litorais e se reconhecem léxicos topológicos que se imiscuem no tecido matérico-conceitual das obras escolhidas para 
nossa análise exigindo que um outro olhar se apresente diante daquilo que emana da imagem vista.

Render-se à imagem, a levar-se em conta o léxico da língua portuguesa é nela tramar-se rendilhados a ecoar a etimologia de texere em que copulam o texto e o têxtil, tramas de sentidos que se revelam ao olhar microscópico e à própria lógica de remissão infinita de textos a textos que se abrem incessantes como na tela de um computador. Como biombos que não cessassem de cruzar-nos o olhar.

Nas obras de Hilal Sami Hilal, os tempos warbuguianos já mencionados na segunda sessão deste texto varam como flechas - que atravessam a carne do tempo - as suas obras, o que se instala na imagem , encarnação que em tudo remonta à materialização da promessa do Cristo em nossa tradição religiosa e evoca em Hilal Sami Hilal a metáfora paterna que figura no nome e não do pai - em francês o "Nom-du-Père" promove a homofonia entre nom (nome) e não (non) a que se atrela o Simbólico em Lacan, a lei e o pacto simbólicos que se evocam no Nomedo-Pai.

Toda a herança paterna da cultura árabe se desdobra em Hilal Sami Hilal, é o que sugere nossa leitura,em filigranas metalizadas que se (des)fiam , como que veios na terra , veios no corpo - a encarnação de que falávamos - como que fios de tramas. Em suas obras, o metal quer-se papíreo, quer-se como se querem pergaminhos que se desfiam, como novelos que se deslindam pluviais, rios oxidados que são as veias da lingua caligráfica árabe herdada do pai de Hilal Sami Hilal.

O espectro paterno que se alumbra no quadro de Turner que aqui se apresentou é o autor sem autoria, o autor assujeitado às estruturas da 
linguagem -há algo ali a que se responde à revelia - o desejo das imagens em sua perturbadora ambivalência (MITCHELL,2005).

O autor que se instalou como fóssil paleontológico, a história como exercício antiquário e arquelógico em Tucídides (GINZBURG, 2002) no dentro da carne plúmbea - o chumbo da obra - a pigmentação oxidada, as águas de tempos de um rio que mais lembram o vaivém menemônico de histórias de outros tempos, tempos até ignorados parcial ou em sua totalidade por aquele que responde nominalmente pela obra. O fantasma do pai de Hilal Sami Hilal é sua ancestralidade inteira instalada num fóssil - as imagens de seu filho, o artista. O sonho de Hilal Sami Hilal é o tecido que se fez carne em sua obra. O lugar pretérito na caligrafia na cultura árabe, os objetos de escrita em tudo assemelhados àqueles com que um dia se pintou. Pintescrituras fantasmais.

O estatuto sagrado que a escrita árabe passa a ocupar a partir da existência do Corão, o livro como objeto e não apenas o texto como mensagem. Ainda que Maomé fosse iletrado (MEDIAVILLA, op.cit.), cerca-se daqueles que podem escrever para inscrever como lei, memória, documento e, igualmente como um objeto a ser contemplado, os textos tornados retinianos e óticos, por assim dizer, as iluminuras, a arte da caligrafia em seus inúmeros estilizações.

Em Rastros de Inscrição, a artista e poeta visual Neide de Sá concentra-se na potência e dimensão visual, tipográfica e caligráfica da escrita. Há nessa série da autora, a revisitação de inscrições, escritas e alfabetos arcaicos. Sá apropria-se de fotocópias de manuscritos antigos e trechos de livros antigos, impressos com tipos de madeiraou com as letras desenhadas em estilo gótico para que o mistério criptográfico aí encerrado possa revelar-se no ato da leitura, ou melhor, que o olhar que contempla 
estas inscrições mergulhe na materialidade quase arqueológica, na aventura morfológica da letra para além de sua clausura representacional. A temporalidade aqui desenha-se sincrônica, o texto - a obra - é varado(a) pela forma (eidos) e códigos que assumem uma concretude visual de escritas produzidas em diferentes momentos da humanidade por culturas distintas. Há um redemoinho, um turbilhão de temporalidades que se cruzam sobrepostos e embaralhados aqui. Ecos de tempos em Warburg (DIDI-HUBERMAN, 2013).
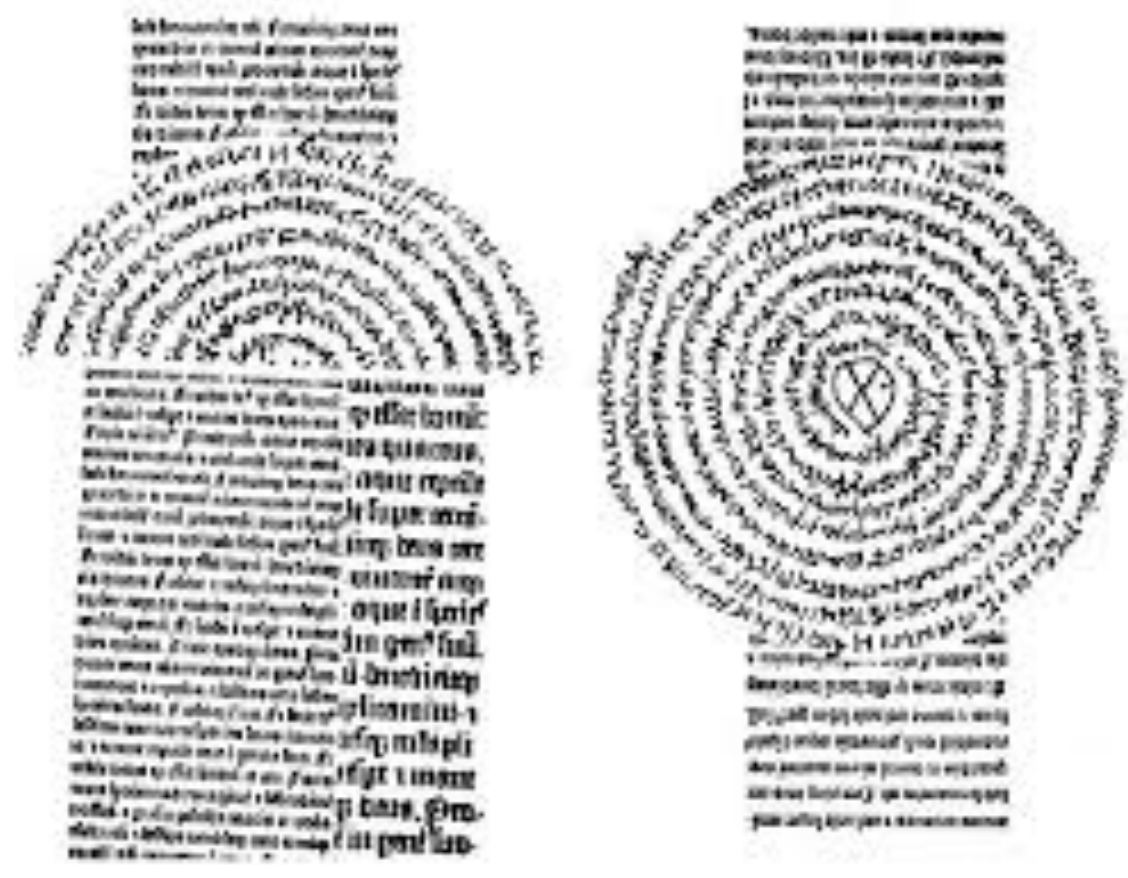

Rastros de Inscrição, Neide Sá , 1988. Corte, colagem. $21 \mathrm{~cm}$ X 29,7cm

Retém-se em Hilal Sami Hilal o pretérito vivo desta materialidade anacrônica, disfarçada e atualizada em seu travestimento contemporâneo. O malemolente impossível da imobilidade pétrea do metal é suavizado pelo rendilhamento a que o artista submete seus objeto-livros. Uma intemporalidade que se revela como um sintoma que se mascara 
metafórico. Insistente como que a reiterar sua singularidade inapreensível nas malhas da linguagem e na sobrevivência e sobrevida metamorfoseada das imagens - Nachleben (WARBURG apud DIDI-HUBERMAN,op.cit., 2013) desejo que se deslinda metonímico na cadeia significante (LACAN, 1998, op.cit. pp.496-536).

Warburg aborda a História da Arte, seria, aliás mais preciso que usássemos o termo por ele cunhado Ciência da Cultura (Kulturwissenschaft) por um viés de feições antropologizantes, o que lhe permite detectar na cultura vigente nos tempos de Lutero ou na retratística renascentista suas Nachleben da Antiguidade pagã, assim como o Pathosformel (as formas patéticas, dramáticas, intensas, algo barroquizantes) que em larga medida contrapõem-se à sophrosynè (a calma temperança) com que a arte grega se associou em Winckelmann, por exemplo.

Warburg assim investe o tecido fenomenológico, hermenêutico e epistemológico da história (RICOEUR, 2000) de ressonâncias sincrônicas. Em Warburg, estamos a falar de uma história de fantasmas a cruzar fronteiras, confundir territórios, atravessar paredes. Estes fantasmas desconhecem e desrespeitam hierarquias. Há neles o centrípeto em detrimento do centrífugo. Não à toa, Warburg guia-se por uma abordagem de leitura em que se abolem as convenções diacrônicas e as petrificações periodizantes em seu Atlas Mnemosyne.

A memória triunfa, os esquecimentos afloram à superfície atônitos em sua sintomatologia. Um painel, uma mesa (mensa) em que, em vez de quadros estáticos, as imagens são moventes, como num jogo de tabuleiro, sem lugares fixos para as peças (imagens). Elas embaralham-se ao sabor de ramificações líquidas, pluviais, rizomático-deleuzianas (DELEUZE \& 
GUATTARI, 1980), há, insistiria Warburg, uma vida nelas (DIDIHUBERMAN, 2015). Há algo que elas querem dizer, insistiria Mitchell (op.cit.2005).

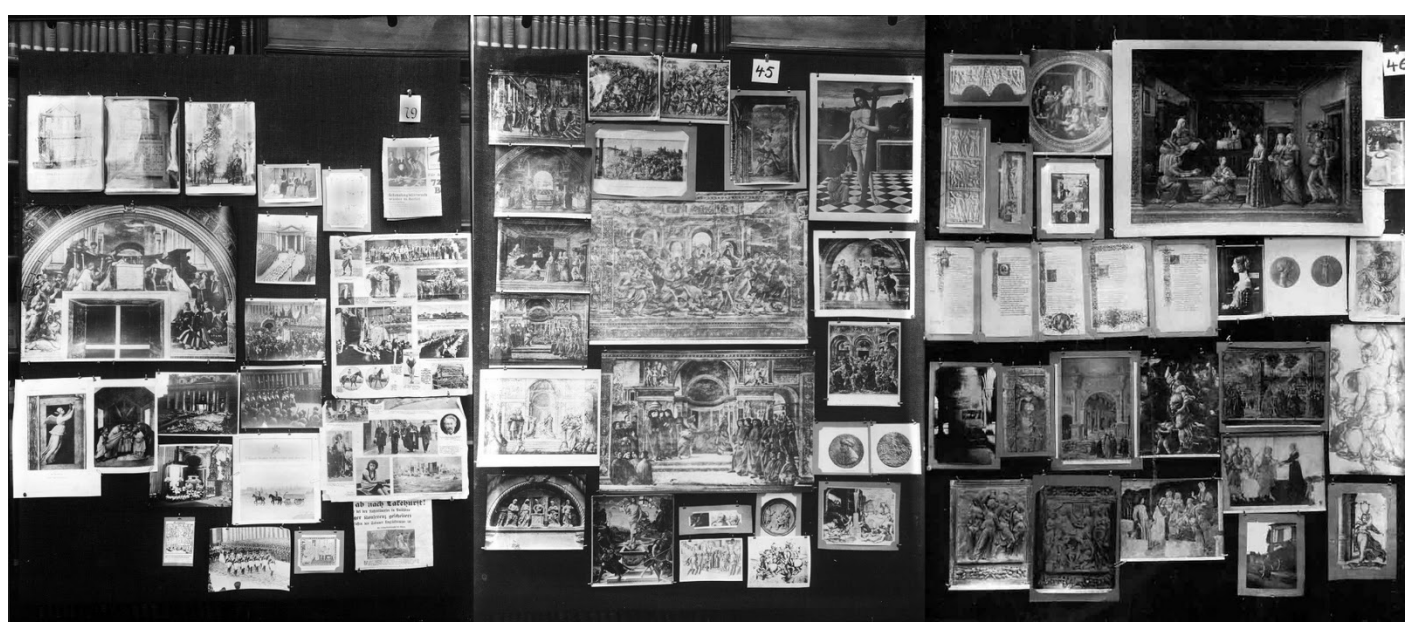

Aby Warburg, Atlas Mnemosyne

E tampouco é fortuito que estas infiltraçoes fantasmáticas de um sintoma caligráfico nos tenham pautado a interpretação que ora se oferece das obras de Hilal Sami Hilal como um compêndio fossilizado de memórias de sua ancestralidade árabe, islâmica. Esta obsessão caligráfica se materializa em uma obsessão com os instrumentos, ferramentas, paramentos de uma quase-liturgia da escrita: os pincéis, a exatidão e elegância gestuais que se devem deixar perceber nas formas caligráficas, os pigmentos, tintas, tinteiros, as técnicas, o tratamento a que se submetem as superficies papíreas de mais difícil falsificação que os pergaminhos, os selos imperiais, a escrita nos murais, nos mosaicos, nas cerâmicas, nos ossos, nas carapaças, a escrita se liberta da forma pergaminho e se deslinda infinita pois que nenhum de nós será o detentor da significação final e conclusiva de uma imagem, texto, de um "texto-imagem": o 
impoderável do artístico-literário para um além de seus embalsamentos pretéritos: o livro como múltiplas imagens vivas, o livro possível da Arte.

Uma literatura que se conta também no icônico, o verbivocovisual de que nos fala a poesia concreta. Poema (des)enterrado ${ }^{146}$, daí as oxidações que se enxergam em seus veios vivos. Caligrafia que se torna sagrada como o livro que a encerra e a mensagem mais fundamental que carrega: poder significar, continuar a significar. Alada, como uma carta ou letra que se rouba ou furta furtivamente (LACAN, 1998) e cujo conteúdo traduz-se em um livro por vir. Uma caligrafia que, se por um lado, perde em lisibilidade, ganha em estética.

É um Hilal Sami Hilal bibliófilo, calígrafo, cartógrafo, encardenador, o livreiro-ourives, um livreiro à maneira de Warburg, que se vê em suas obras. Não espanta que se as batizem, pois, assim: Atlas (um conjunto de monotipias - pinturas - sem a intervenção da mão do artista na composição das massas de névoas cromático-pictóricas que constituem este verdadeiro livro warburguiano), Bibliotecas, Livros Redondos, Sherazades, Cartas.

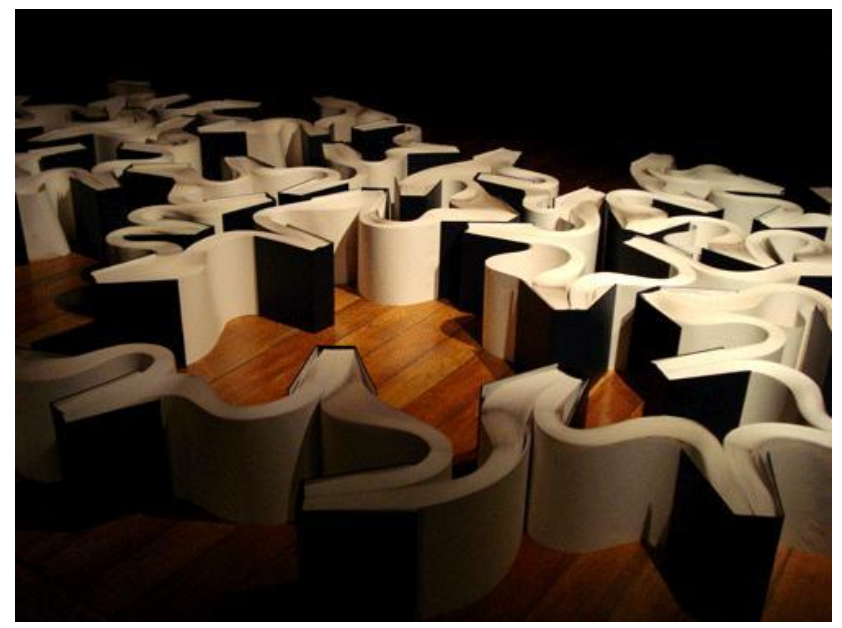

Sherazade, Hilal Samil Hilal, 2007.

146 Referência ao Poema Enterrado, de Ferreira Gullar. 
VIS

Revista do Programa de Pós-graduação em Arte da UnB

Contratos que se assinam à revelia de seus signatários, um contratoassinado que se lê ao sabor do(s) tempo(s) da imagem. Eikon e Phantasia, formula inescapável. “Texto-Imagem”oxidado.

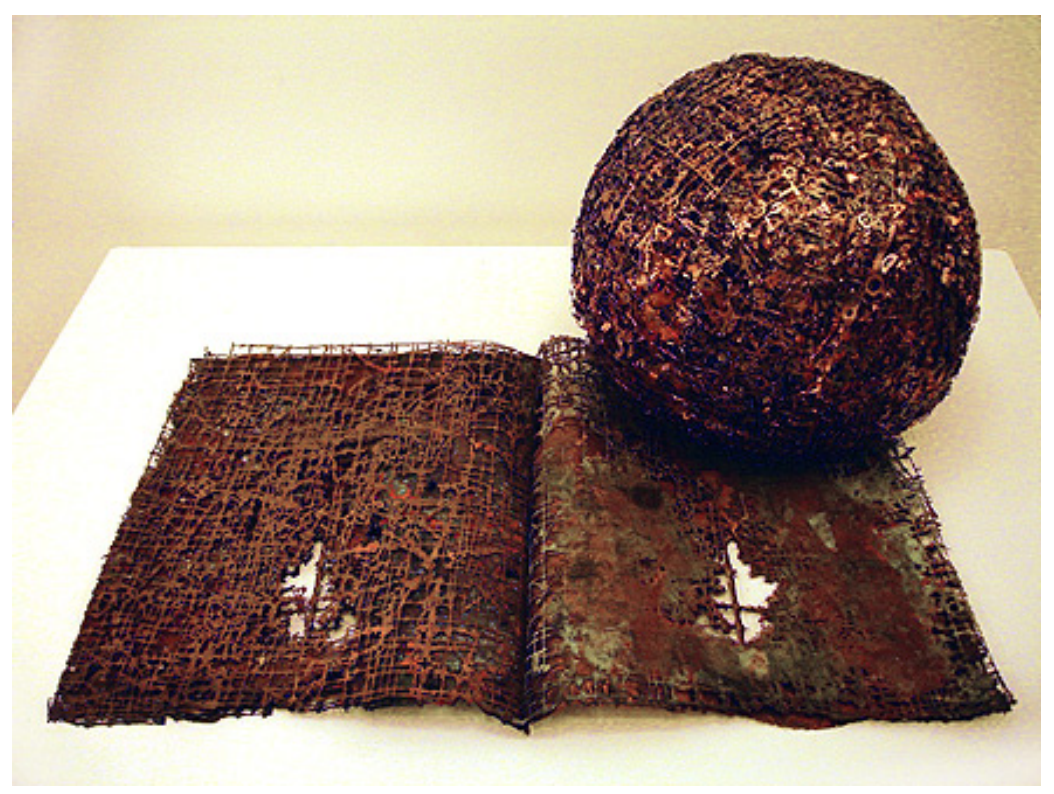

Bibliotecas, Hilal Sami Hilal.

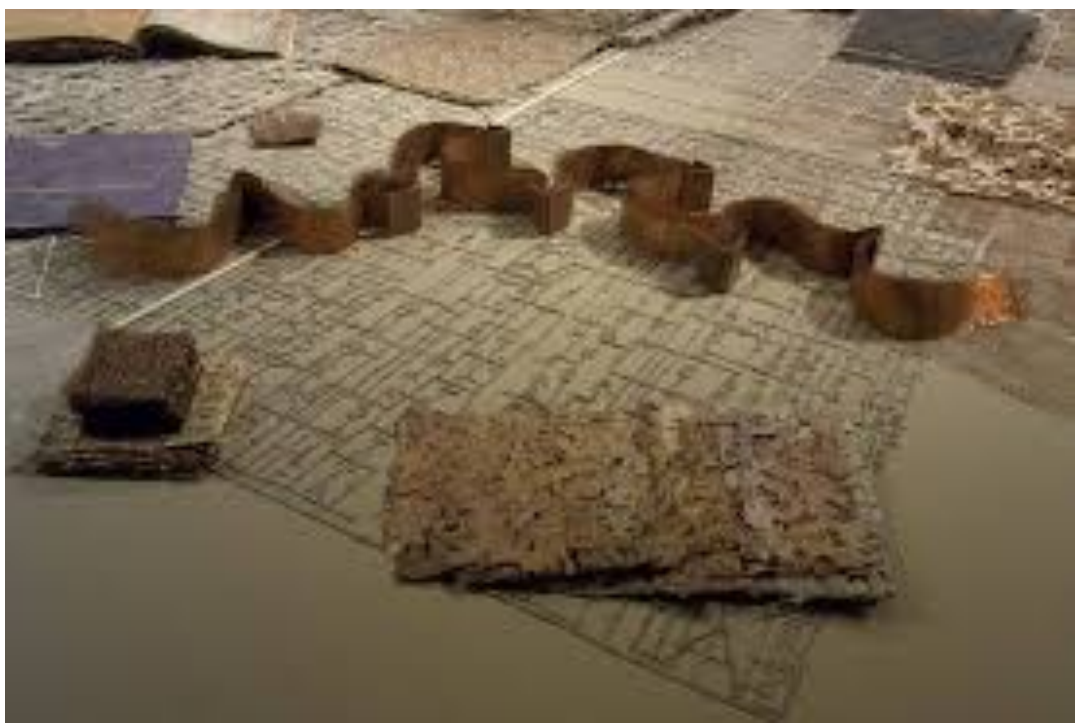

Bibliotecas, Hilal Sami Hilal.

Pintescritura: Rébus. 


\section{Referências}

ARAÚJO, Ricardo. Poesia Visual, Video-Poesia. São Paulo: Perspectiva, 1999. ARISTÓTELES. Poética. Lisboa: Imprensa Nacional Casa da Moeda, 2010. DIDI-HUBERMAN, Georges. A imagem sobrevivente: história da arte e tempo dos fantasmas segundo Aby Warburg. Rio de Janeiro: Contraponto, 2015. Atlas ou a gaia ciência inquieta. Lisboa: KKYM,2013.

FREUD, Sigmund. A interpretação dos sonhos. Rio de Janeiro, Imago, 2001 GINZBURG, Carlo. Relações de força - História, retórica, prova. São Paulo: Companhia das Letras, 2002. p.13-63.

GULLAR, Ferreira. Experiência neoconcreta: momento limite da arte. São Paulo: Cosac \& Naify, 2007.

HANSEN, João Adolfo. Alegoria - construção e interpretação da metáfora. Campinas: UNICAMP, 2006.

LACAN, Jacques. "Lituraterra" IN: Outros escritos. Rio de Janeiro: Zahar, 2003. p. 15-29.

" “O seminário sobre a carta roubada" IN: Escritos. Rio de

Janeiro: Zahar, 1998.

LESSING, G.E. Laocoonte ou sobre as fronteiras da pintura e da poesia. São Paulo: Iluminuras, 2011.

LICHTENSTEIN, Jacqueline (org.). A pintura. Vol. 7 : o paralelo das artes. São Paulo: 34, 2005.

MASSOUDY, Hassan \& Isabelle. L'ABCdaire de la calligraphie árabe. Paris: Flammarion, 2003.

MEDIAVILLA, Claude. L'ABCdaire de la calligraphie chinoise. Paris: Flammarion, 2004.

MITCHELL, W.J. T. Iconology - image, text, ideology. Chicago: University of Chicago Press, 1986. 
. Image Science - iconology, visual culture and media aesthetics.

Chicago, University of Chicago Press, 2015.

. Picture Theory. Chicago: The University of Chicago Press,

1994.

What do pictures want?. Chicago: The University of Chicago

Press, 2005.

NAVAS, Adolfo Montejo. “ Os metassignos em Neide Sá” In: Do poema visual ao objeto-poema - a trajetória de Neide Sá. Rio de Janeiro: Lacre, 2014. pp. 10-12.

RICOEUR, Paul. La mémoire, l'histoire, l'oubli. Paris: Seuil, 2000.

SCHWARTZ, Jorge \& MONZANI, Marcelo (org.). Atlas: Hilal Sami Hilal. São Paulo: Imprensa Oficial do Estado de São Paulo, 2010.

VIEIRA, Marco Antônio. “De um Lacan em Lituraterra: Pintescritura em W(o)olf e Green(a)way". Brasília, 2004. Dissertação de Mestrado em Teoria Literária. TEL, IL, UnB.

WARBURG, Aby. Histórias de fantasmas para gente grande. São Paulo: Cia das Letras, 2014. 